\title{
Highly efficient differentiation of neural precursors from human embryonic stem cells and benefits of transplantation after ischemic stroke in mice
}

Danielle Drury-Stewart ${ }^{1,2}$, Mingke Song ${ }^{1}$, Osama Mohamad', Ying Guo ${ }^{3}$, Xiaohuan Gu', Dongdong Chen ${ }^{1}$ and Ling $\mathrm{Wei}^{1^{*}}$

\begin{abstract}
Introduction: Ischemic stroke is a leading cause of death and disability, but treatment options are severely limited. Cell therapy offers an attractive strategy for regenerating lost tissues and enhancing the endogenous healing process. In this study, we investigated the use of human embryonic stem cell-derived neural precursors as a cell therapy in a murine stroke model.

Methods: Neural precursors were derived from human embryonic stem cells by using a fully adherent SMAD inhibition protocol employing small molecules. The efficiency of neural induction and the ability of these cells to further differentiate into neurons were assessed by using immunocytochemistry. Whole-cell patch-clamp recording was used to demonstrate the electrophysiological activity of human embryonic stem cell-derived neurons. Neural precursors were transplanted into the core and penumbra regions of a focal ischemic stroke in the barrel cortex of mice. Animals received injections of bromodeoxyuridine to track regeneration. Neural differentiation of the transplanted cells and regenerative markers were measured by using immunohistochemistry. The adhesive removal test was used to determine functional improvement after stroke and intervention.

Results: After 11 days of neural induction by using the small-molecule protocol, over 95\% of human embryonic stem-derived cells expressed at least one neural marker. Further in vitro differentiation yielded cells that stained for mature neuronal markers and exhibited high-amplitude, repetitive action potentials in response to depolarization. Neuronal differentiation also occurred after transplantation into the ischemic cortex. A greater level of bromodeoxyuridine co-localization with neurons was observed in the penumbra region of animals receiving cell transplantation. Transplantation also improved sensory recovery in transplant animals over that in control animals.

Conclusions: Human embryonic stem cell-derived neural precursors derived by using a highly efficient smallmolecule SMAD inhibition protocol can differentiate into electrophysiologically functional neurons in vitro. These cells also differentiate into neurons in vivo, enhance regenerative activities, and improve sensory recovery after ischemic stroke.
\end{abstract}

Keywords: Human embryonic stem cell, Neural precursor, Electrophysiology, Stem cell, Cell therapy, Ischemic stroke, Neurogenesis, Small molecule

\footnotetext{
* Correspondence: Iwei7@emory.edu

1Department of Anesthesiology, Emory University, 101 Woodruff Circle,

Atlanta, GA 30322, USA

Full list of author information is available at the end of the article
} 


\section{Introduction}

Each year, approximately 795,000 people in the United States experience a stroke and it is now the fourth leading cause of death when considered separately from other cardiovascular diseases. It is also a leading cause of disability, and $26 \%$ of stroke survivors over 65 are still dependent on others for daily activities at 6 months after stroke [1]. However, administration of tissue plasminogen activator in the acute phase of stroke is still the only US Food and Drug Administration-approved treatment for this prevalent cause of death and morbidity and its application is limited by a narrow therapeutic window and a number of complications [2]. Other drugs that mediate significant neuroprotection in animal models and small trials, such as erythropoietin, have failed to demonstrate efficacy in large-scale human clinical trials [3].

Studies on treatment in the chronic phase of stroke are generally focused on recovering function through tissue repair and regeneration. Cell therapy is an attractive strategy for these goals, as transplanted cells may replace dead or damaged cells in addition to providing trophic support to supplement endogenous healing [4-6]. Various types of neural precursors, such as a conditionally immortalized cell line derived from human fetal tissue (now in clinical trials) [7-10], lines derived from carcinomas [11,12], fetal neuronal stem cells [13,14], mouse neural precursors derived from the post-stroke cortex [15], region-specific murine embryonic precursors [16], and precursors derived from mouse [17-19] or human [20-26] embryonic stem cells have been used in experimental models.

Human embryonic stem (hES) cells are pluripotent and can proliferate indefinitely in culture, both useful properties in the context of cell therapy. However, although neural differentiation is often seen as the default pathway for these cells [27], directed differentiation is difficult to optimize. Common neural differentiation protocols often use suspension culture techniques [28-33] or co-culture with feeder cells $[31,34,35]$, both of which can introduce heterogeneous microenvironmental cues. Feeder cells, which are generally of rodent origin, also introduce xenogenic contaminants that can increase the immunogenicity of transplanted cells. Additionally, expensive recombinant factors like noggin are often used to obtain neural precursors [29,36-38], and the expense associated with these factors can be a limiting factor in scaling up cultures to the level required for preclinical development. More recently, there has been a greater focus on the use of fully adherent protocols [37] and small molecules [39] to cut down on heterogeneity and cost.

We previously reported the use of a fully adherent differentiation protocol that relies primarily on small molecules for differentiation, reducing the cost and heterogeneity in in vitro differentiation of neural precursors and neurons
[40]. In the present study, we further characterize the in vitro differentiation of cells by using this protocol and demonstrate the use of hES cell-derived neural precursors in a murine model of ischemic stroke. We demonstrate that neural precursors derived by this method provide a useful cell population for cell-based stroke therapy.

\section{Methods}

\section{Human embryonic stem cell maintenance and} differentiation

H1 hES cells (p35-50; WiCell, Madison, WI, USA) were maintained on hES cell-qualified Matrigel (BD Biosciences, Sparks, MD, USA)-coated dishes in mTeSR1 medium (Stem Cell Technologies, Vancouver, BC, Canada). Differentiation was carried out as previously described [40]. Briefly, neural precursors were obtained by using a modified version of the differentiation protocol developed by Chambers and colleagues [37]. The neural precursors were seeded as single cells on growth factor reduced Matrigel (BD Biosciences)-coated dishes and grown to adherence, and SMAD inhibition was applied by using dorsomorphin (Tocris, Ellisville, MO, USA) and SB431542 (Stemgent, Cambridge, MA, USA). For in vitro differentiation of neurons, neural precursors were re-seeded as single cells and grown in a mixture of N2 and B27 medium (Invitrogen Corporation, Carlsbad, CA, USA) supplemented with 10 $\mathrm{ng} / \mathrm{mL}$ basic fibroblast growth factor (bFGF) (R\&D Systems, Minneapolis, MN, USA).

Differentiation was partially confirmed by staining by using standard protocols [41]. Cells were fixed in $4 \%$ paraformaldehyde (Sigma-Aldrich, St. Louis, MO, USA), permeabilized by using Triton-X-100 (G-Biosciences, St. Louis, MO, USA), blocked by using $1 \%$ fish gelatin (Sigma-Aldrich), and primary antibodies (nestin, neuronal nuclei (NeuN), neurofilament L (NF); Millipore, Billerica, MA, USA; paired box gene 6 (PAX6): Covance, Princeton, NJ, USA; sex-determining region Y-box 1 (SOX1): Santa Cruz Biotechnology, Santa Cruz, CA, USA) were applied overnight at $4^{\circ} \mathrm{C}$ in phosphatebuffered saline. Cy3- or Alexafluor 488-conjugated antibodies were applied for 1 to 2 hours at room temperature, and Hoechst 33324 (Invitrogen Corporation) or 4',6-diamidino-2-phenylindole (DAPI) (Vector Labs, Burlingame, CA, USA) was used to counterstain nuclei. Cells expressing neural precursor markers were quantified by using the ImageJ cell counter, and at least 7,000 cells were counted per sample and no fewer than three samples were counted per marker.

Some antibodies were selected for Western blot analysis. Protein $(30 \mu \mathrm{g})$ from each sample was loaded into a gradient gel and run at constant current until protein markers had adequately separated. They were transferred onto polyvinyl difluoride membranes that were then probed by using standard protocols. Primary antibodies 
(Actin, Sigma-Aldrich; glial fibrillary acidic protein (GFAP), Thermo Fisher Scientific, Waltham, MA, USA; GluA2, GluN3A, nestin, Millipore; GluN1, Cell Signaling, Danvers, MA, USA; Nav1.1, Abcam, Cambridge, MA, USA) were applied overnight at $4^{\circ} \mathrm{C}$. Alkaline phosphatase (AP)- or horseradish peroxidase (HRP)-conjugated secondary antibodies were applied for 1 to 2 hours at room temperature. AP-conjugated antibodies were developed by using nitroblue tetrazolium and 5-bromo-4-chloro-3'-indolyphosphate (NBT/BCIP) solution, and HRP-conjugated antibodies were developed by using a Pierce ECL Detection Kit (Thermo Fisher Scientific). Actin was used as a loading control.

\section{Electrophysiological recording of differentiating cells}

Whole-cell patch clamp recording was performed on cultured cells exhibiting neuronal morphology at 7, 14, 21, and 28 days after re-seeding. The measurements were performed as in our previous studies by using an EPC9 amplifier (HEKA Elektronik, Lambrecht, Germany) at room temperature [42]. The external solution $(\mathrm{pH}=7.4)$ contained $135 \mathrm{mM} \mathrm{NaCl}, 5 \mathrm{mM} \mathrm{KCl}, 2 \mathrm{mM} \mathrm{MgCl} 2,1 \mathrm{mM}$ $\mathrm{CaCl}_{2}, 10 \mathrm{mM}$ HEPES, and $10 \mathrm{mM}$ glucose. The internal solution ( $\mathrm{pH}=7.2$ ) contained $120 \mathrm{mM} \mathrm{KCl}, 2 \mathrm{mM} \mathrm{MgCl}_{2}$, $1 \mathrm{mM} \mathrm{CaCl}_{2}, 2 \mathrm{mM} \mathrm{Na}_{2} \mathrm{ATP}, 10 \mathrm{mM}$ EGTA, and $10 \mathrm{mM}$ HEPES. Recording electrodes were pulled from borosilicate glass pipettes (Sutter Instrument, Novato, CA, USA) and had a tip resistance of between 5 and $7 \mathrm{M} \Omega$ when filled with the internal solution. Series resistance was compensated by $75 \%$ to $85 \%$. Linear leak and residual capacitance currents were subtracted online by using a $\mathrm{P} / 6$ protocol. Action potentials were triggered by depolarization pulses and recorded under current-clamp mode by using PULSE software (HEKA Elektronik), and data were filtered at $3 \mathrm{KHz}$ and digitized at a sampling rate of $20 \mathrm{KHz}$.

Delayed rectifier potassium current densities $\left(\mathrm{I}_{\mathrm{K}}\right)$ were recorded from -60 to $+60 \mathrm{mV}$ with a $20 \mathrm{mV}$ increment and a holding potential of $-70 \mathrm{mV}$ in the presence of 0.5 $\mu \mathrm{M}$ tetrodotoxin to block sodium currents. The reported current densities were measured at $+40 \mathrm{mV}$. Transient outward potassium current densities $\left(\mathrm{I}_{\mathrm{A}}\right)$ were elicited from -60 to $+40 \mathrm{mV}$ with a $20-\mathrm{mV}$ increment after a hyperpolarization of $-110 \mathrm{mV}$ for $500 \mathrm{~ms}$. Peak amplitudes were measured at $+40 \mathrm{mV}$. Both current measurements were normalized to cell size by using the capacitance of the cell.

\section{Ischemic stroke and cell transplantation}

All procedures were approved by the Institutional Animal Care and Use Committee and met National Institutes of Health guidelines. Male 8- to 12-week-old C57/B16 mice were subjected to a focal ischemic stroke as previously described [41,43-45]. Briefly, during anesthesia with $2 \%$ chloral hydrate, a $2.0-$ to $2.5-\mathrm{mm}$-diameter craniectomy was performed through the right parietal skull, and the transparent dura was left intact over the whisker barrel cortex. Four to five distal branches of the middle cerebral artery serving the barrel cortex were ligated by using a 10-O suture through the dura. The creation of the whisker barrel ischemic region was completed by bilateral occlusion of the common carotid arteries (CCAs) for 7 minutes followed by reperfusion. Blood flow reduction was confirmed (Figure 1) by using the PeriScan PIM II Laser Doppler perfusion imager (Perimed AB, Cleveland, OH, USA) during the 7-minute ligation of the CCAs. This stroke model is focused on the whisker barrel cortex but also affects the forelimb region of the sensorimotor cortex.

Cell transplantation was carried out 7 days after stroke. Cells were labeled with a 1-hour exposure to $10 \mu \mathrm{g} / \mathrm{mL}$ Hoechst 33324 and treated with accutase to obtain a single-cell suspension. Cells were filtered through a $20-\mu \mathrm{m}$ mesh and resuspended in N2 medium. Animals were reanesthetized with $2 \%$ chloral hydrate. The ischemic infarction is well developed at this time, and the ischemic core (white or pale region) and peri-infarct area can be directly identified under an operating microscope through the cranial window. Injection of $4 \mu \mathrm{L}$ of cell suspension (transplant group, 200,000 cells total) or medium (control group) into the core and penumbra regions of the stroke area was performed by using a Hamilton $8033070110-\mu \mathrm{L}$ removable-needle syringe (Hamilton Company, Reno, NV, USA). Four injection sites (two in the core and two in the penumbra, $1 \mu \mathrm{L}$ each) were used and each was carried out slowly (total injection time of 10 minutes). The needle was kept in the injection site for 2 minutes before withdrawal to prevent backflow of the injected solution. On the day of the transplant, animals began receiving daily intraperitoneal injections of $50 \mathrm{mg} / \mathrm{kg}$ bromodeoxyuridine (BrdU) (Sigma-Aldrich) to label proliferating cells. These injections were continued until sacrifice. Animals received no immunosuppression. Two to three days after injection, one transplant animal per group $(\mathrm{n}=4)$ was sacrificed to assess graft survival. Staining was carried out on 10- to $20-\mu \mathrm{m}$ sections by using the vendor instructions (DeadEnd $^{\mathrm{Tm}}$ Fluorometric TUNEL System; Promega Corporation, Madison, WI, USA).

\section{Immunohistochemistry}

Animals were sacrificed 28 days after transplantation and brains were fresh-frozen in optimal cutting temperature compound (OCT) (Sakura Finetek, Torrance, CA, USA). Each $10-\mu \mathrm{m}$ section on a slide was at least $100 \mu \mathrm{m}$ from the previous section to avoid doublecounting of cells, and slides were light-protected to preserve the Hoechst 33342 label. Slides were stained by using standard protocols for NeuN (Millipore) to label neurons, collagen IV (Col IV) (Millipore) to label vessels, or BrdU (AbD Serotec, Oxford, UK) to label newborn 

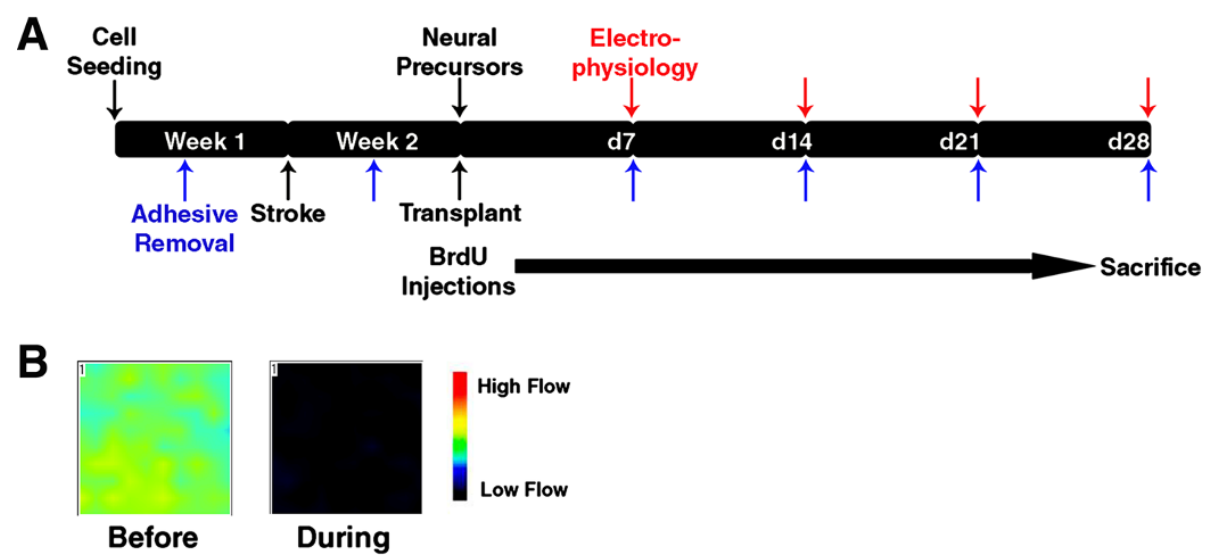

Figure 1 Cell differentiation and stroke model. (A) Timeline of the differentiation process, stroke induction, and testing. Neural precursors were obtained approximately 2 weeks after seeding, and electrophysiology measurements were carried out every 7 days after re-plating. Transplantation was carried out at the neural precursor stage, 1 week after stroke induction. Adhesive removal training took place in the week before stroke. Testing was carried out 4 days after stroke and then 7, 14, 21, and 28 days after transplantation. BrdU injections were given daily beginning on the day of transplantation. (B) Representative blood flow measurements before and during the 7-minute ligation of the CCA, demonstrating a nearly complete blood flow reduction to the affected area.

cells. Pictures were taken by using fluorescence microscopy along the length of the penumbra region defined morphologically as the region just outside the stroke core. Z-stack imaging was used to confirm colocalization. At least three sections per sample were quantified for each measurement. Where possible, human cells were identified by the Hoechst tag applied before transplantation.

\section{Hoechst-positive cell counting in brain sections}

Cell count of Hoechst-positive cells remaining in the graft at 28 days was performed by following a modification of the principles of design-based stereology. Systematic random sampling was employed to ensure accurate and non-redundant cell counting. Every section under analysis was at least $100 \mu \mathrm{m}$ away from the next. For each animal, six $10-\mu$ m-thick sections spanning the entire region of interest that crossed $600 \mu \mathrm{m}$ around the ischemic core/peri-infarct region were counted. The total number of Hoechst-positive cells on the six sections of each slide was quantified.

\section{Behavioral testing}

Starting several days before stroke, animals were trained in the adhesive removal task [46] until they could consistently completely remove the adhesive dot from both forepaws within 12 seconds. Both the time to contact and time to remove the dot after contact were recorded. Performance in this task was then measured 4 days after stroke to obtain a baseline measurement for impairment. Animals showing no impairment on the affected side were rare and were removed from further behavioral study. Testing was repeated 7, 14, 21, and 28 days after transplantation by an investigator blinded to the treatment groups.

\section{Statistical analysis}

In vitro staining data are reported as the mean percentage \pm standard deviation of cells positive for a marker. Peak voltage and current density values are reported as mean \pm standard error of the mean (SEM) and were compared by using analysis of variance with a Tukey post hoc test. Peak voltage measurements of action potentials are pooled from cultures at $5 \%$ and $20 \% \mathrm{O}_{2}$ tension. For in vivo immunohistochemical data, the values of mean \pm SEM were compared by using a Student $t$ test. Normal distribution was confirmed by using the Kolmogorov-Smirnov test.

A compound symmetry variance-covariance form in repeated measurements was assumed for each behavioral outcome. A signed rank test was used to determine the significance of post-stroke impairment. Post-stroke baseline measurements were compared between the control and transplant groups by using the Mann-Whitney $U$ test. A repeated measures analysis using linear mixed models via SAS Proc Mixed (version 9.2; SAS Institute Inc., Cary, NC, USA) was performed for the longitudinal measurements of the time to contact and time to remove obtained at $7,14,21$, and 28 days. The fixed effects in the models include the subject's treatment group, time point, and interactions between treatment group and time point. The models also include the poststroke baseline outcome measure (taken at 4 days) and the outcome measure of the unaffected forepaw at the 
same time point. These effects provide adjustment for different post-stroke performance levels across subjects and learning effects across time. The mixed linear models also include the subject-specific random intercept to account for between-subject random variability in outcome measures. All statistical tests were two-sided.

\section{Results}

Immunocytochemistry reveals highly efficient

differentiation of neural precursors

Neural differentiation of H1 hES cells was carried out by using a fully adherent SMAD inhibition protocol employing small molecules $[37,40]$. After 11 days of SMAD inhibition, cells had lost all detectable expression of pluripotency markers and had begun expressing neural precursor markers such as nestin, PAX6, and SOX1. Nestin is an intermediate filament protein that is expressed in the embryonic neuroepithelium and in neural precursors throughout the central nervous system $[47,48]$. PAX6 is an important transcription factor in cortical development $[49,50]$ and is necessary for the development of the thalamocortical tract [51]. We previously reported the expressions of these markers after SMAD inhibition with SB431542 and dorsomorphin as $96 \% \pm 3 \%$ and $75 \% \pm 7 \%$, respectively [40]. In the present study, we examined the expression of SOX1, another transcription factor indicated in the specification of early neural cell fate [52]. This marker was expressed in $64 \% \pm 9 \%$ of cells after 11-day differentiation (Figure 2A). Taken together, these markers indicate efficient differentiation into neural precursors, and most of the cells are biased toward a forebrain lineage.

Staining was also used to verify the ability of these neural precursor cells to differentiate into neurons in vitro. In a mixture of N2 and B27 media, cells formed well-connected networks expressing NeuN and NF (Figure 2B). These cells also expressed $\beta$-III tubulin and microtubule-associated protein 2 (MAP2) (data not shown). The neuronal markers were evident as early as 7 days after re-plating for terminal differentiation (Figure 2B-a) and persisted through 4 weeks of culture (Figure 2B-b,c). In addition to these general markers, cells with a neuronal morphology expressed the 2amino-3-(3-hydroxy-5-methyl-isoxazol-4-yl)propanoic acid (AMPA) receptor subunit GluA1 and the N-methylD-aspartic acid (NMDA) receptor subunit GluN2B (Figure 2C). Western blotting also revealed the presence of the NMDA receptor subunits GluN1 and GluN3A (Figure 2C-c), the AMPA receptor subunit GluA2, and the sodium channel subunit (Nav1.1) (data not shown). Nestin
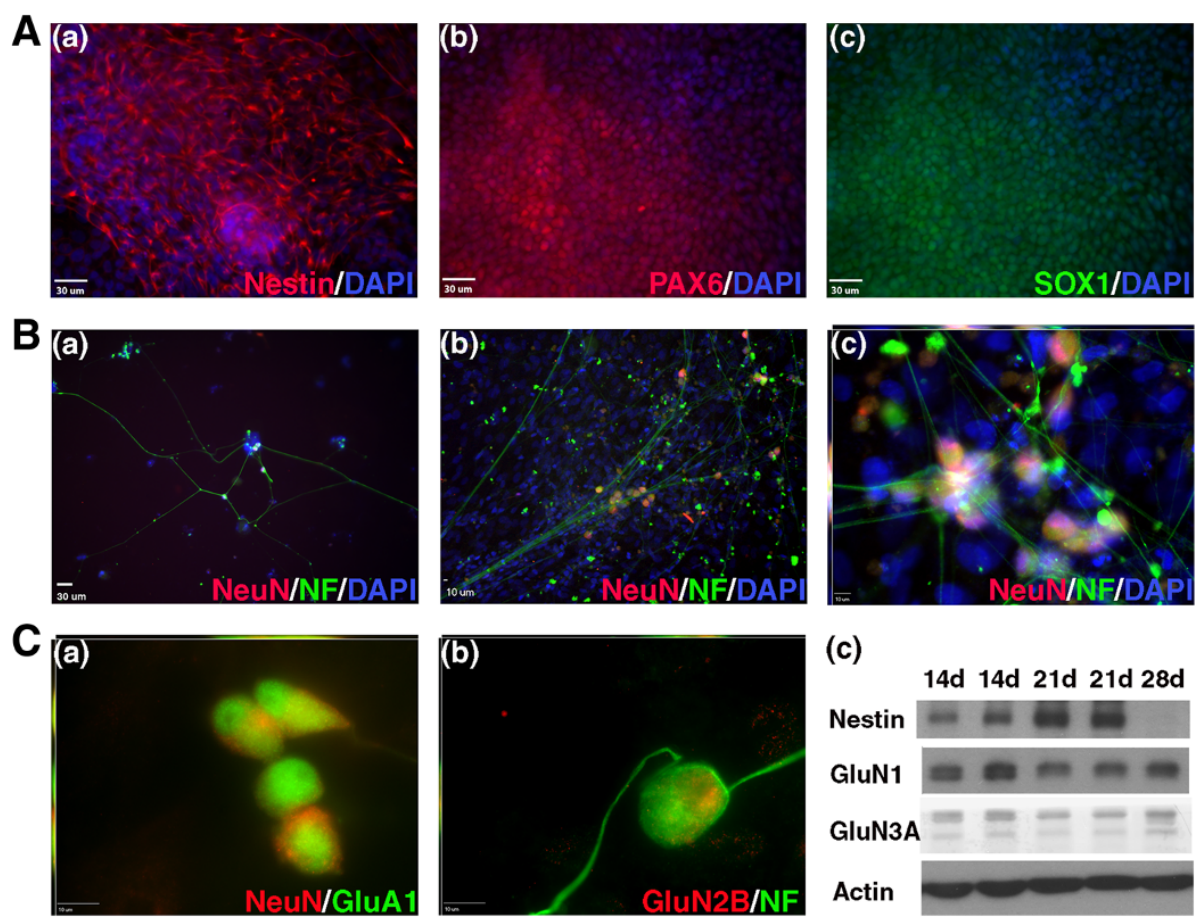

(c)

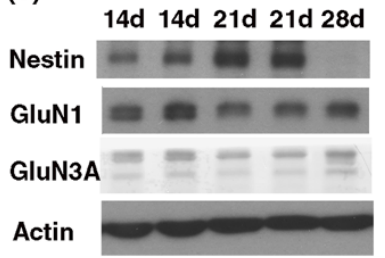

Figure 2 hES cell-derived precursors express neural markers and differentiate into mature neurons in vitro. (A) Neural precursors at day 11 after the beginning of SMAD inhibition; $96 \% \pm 3 \%$ of cells expressed nestin $(n=4), 75 \% \pm 7 \%$ expressed PAX6 $(n=4)$, and $64 \% \pm 9 \%$ expressed SOX1 $(n=3)$. Scale bars are $30 \mu \mathrm{m}$. (B) After re-plating for terminal differentiation, cells positive for NeuN (red) and NF (green) were evident after 7 days (a) and persisted through 28 days (b). These cells formed large networks across the culture, and co-localization of NeuN and NF was evident (c). Scale bars are $10 \mu \mathrm{m}$. (C) At 28 days, cells expressed the AMPA and NMDA receptors GluA1, GluN1, GluN2B, and GluN3A. GluA1 and GluN2B are shown co-localized with NeuN and NF, respectively. Nestin was still present in these cultures through 21 days. Scale bars are $10 \mu \mathrm{m}$. 
expression was still present in the cultures at days 14 and 21 , suggesting that some of the underlying cells were still precursors. However, this expression was lost by day 28 (Figure 2C-c). GFAP was also detected by Western blotting at 14, 21, and 28 days of terminal differentiation, suggesting astrocytic differentiation (not shown).

\section{Human embryonic stem cell-derived neuronal cells display functional electrophysiological properties in vitro} To measure electrophysiological function in hES cell-derived neuronal cells, we performed whole-cell patch-clamp recording over the course of 4 weeks of differentiation. Action potentials displayed a pattern of maturation over the 4-week differentiation period (Figure 3). At 1 week, the evoked response was slow and weak, and the mean amplitude was $33.2 \pm 3.2 \mathrm{mV}$. After 2 weeks of terminal differentiation, most cells fired significantly stronger action potentials with single sharp spikes at a mean amplitude of $69.1 \pm 1.7 \mathrm{mV}$. Further maturation increased this response to a mean amplitude of $78.0 \pm$ $2.0 \mathrm{mV}$ at 3 weeks, and there was no further significant change at 4 weeks. Three weeks of terminal differentiation was also the point at which repetitive trains of action potentials were first observed, and approximately 1 out of 7 of cells exhibited multiple action potentials in response to a single depolarization event. Although no significant change in amplitude was observed from 3 to 4 weeks of differentiation, the proportion of cells firing repetitive trains increased to approximately 1 out of 3 of the cells examined. Miniature excitatory post-synaptic potentials were evident in cultures at all measured time points (data not shown), indicating functional synapse formation between cells.

We also examined changes in potassium currents in differentiating cells (Figure 4). The delayed outward rectifier current density declined over time with neuronal differentiation, from $206.6 \pm 36.4 \mathrm{pA} / \mathrm{pF}$ at 1 week to $111.2 \pm 13.2 \mathrm{pA} / \mathrm{pF}$ at 2 weeks. This decreasing trend continued over time, but no further statistically significant change was observed between weeks 3 and 4 of terminal differentiation. The fast transient outward current density, on the other hand, increased over time. Very small current densities of $3.6 \pm 0.5 \mathrm{pA} / \mathrm{pF}$ were observed at 1 week, increasing to $35.4 \pm 4.3 \mathrm{pA} / \mathrm{pF}$ at 2 weeks and $80.2 \pm 6.0 \mathrm{pA} / \mathrm{pF}$ at 3 weeks into terminal differentiation. Again, no further change was noted at 4 weeks of differentiation. It is likely that the increased role of the transient outward $\mathrm{K}^{+}$current contributed to the maturation of the action potential response by allowing cells to repolarize more quickly.

\section{Human embryonic stem cell-derived neural precursors survive and differentiate into neurons in vivo}

$\mathrm{hES}$ cell-derived neural progenitors were transplanted into the ischemic core and penumbra regions 7 days after ischemic stroke. Two to three days after transplantation, one animal per group $(n=4)$ was sacrificed to check for cell survival. Transplanted cells were identified
A

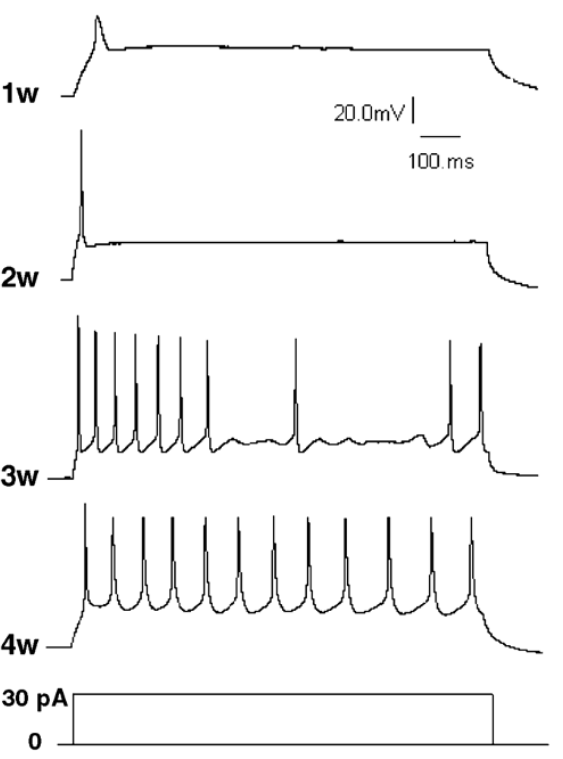

B Action Potential Maturation

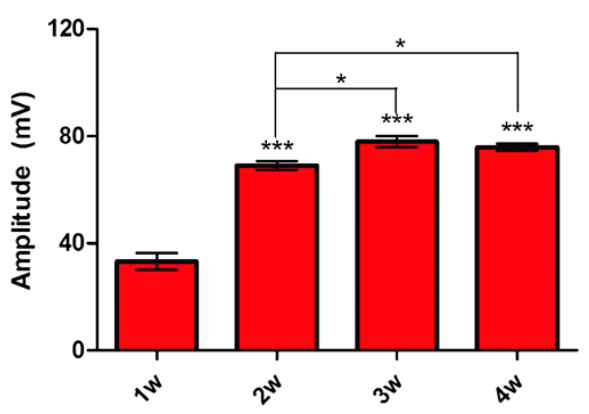

Figure 3 hES cell-derived neurons exhibit mature action potential responses. (A) Representative traces of action potentials fired in response to depolarization at 1, 2, 3, and 4 weeks after re-plating for terminal differentiation. Approximately 1 out of 7 and 1 out of 3 cells fired repetitive trains of action potentials at 3 and 4 weeks, respectively. (B) Quantification of the maximum action potential amplitude presented as mean \pm SEM. A significant increase was observed from 1 to 2 weeks and again from 2 to 3 weeks. $n=19(1 \mathrm{w}), 23(2 \mathrm{w}), 26(3 \mathrm{w})$, and $47(4 \mathrm{w})$. ${ }^{*} P<0.05$, ***P $<0.001$. 

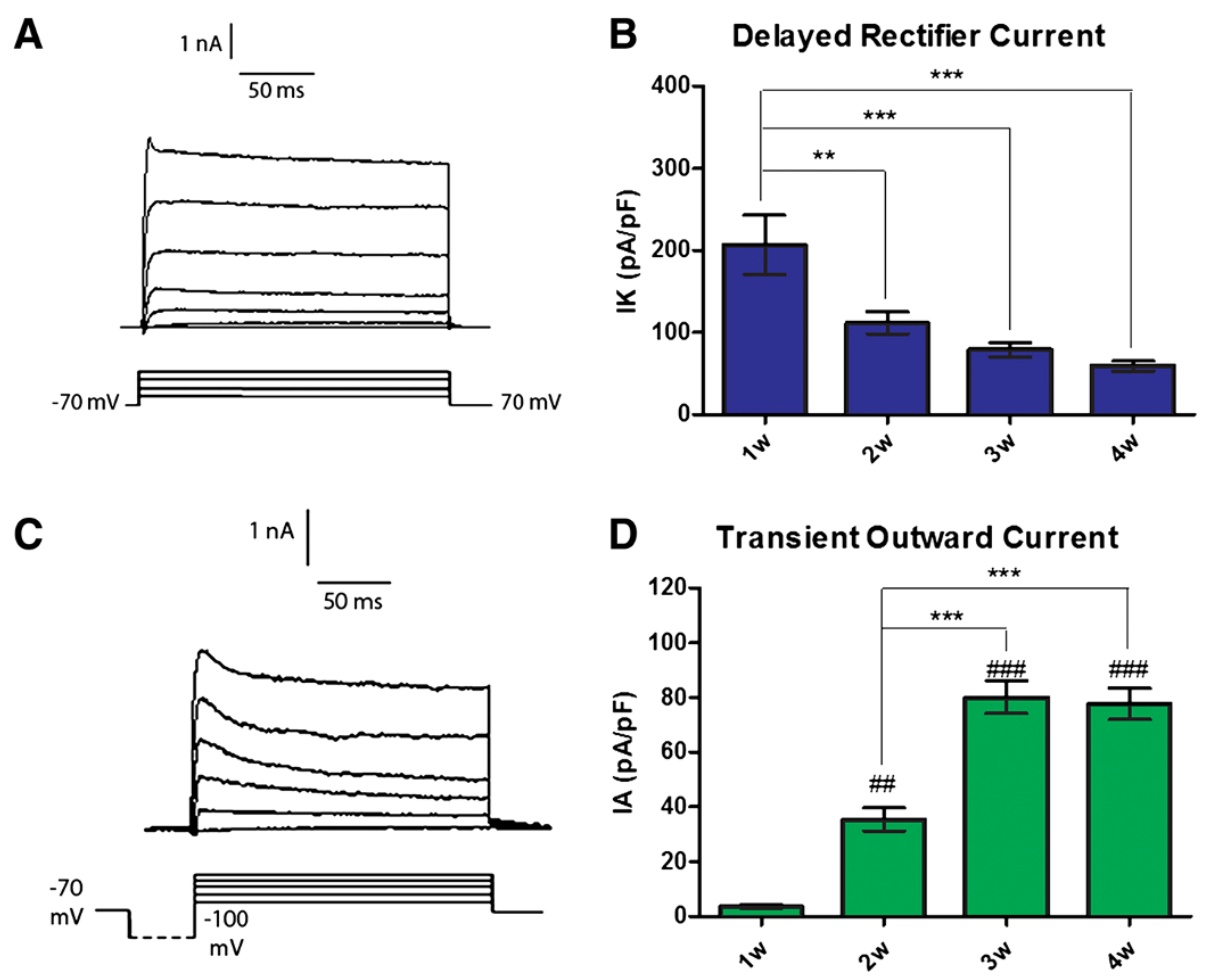

Figure 4 Potassium currents in hES cell-derived neurons mature over 4 weeks in culture. (A) Representative traces of the delayed rectifier $\mathrm{K}^{+}$current in hES cell-derived neurons. (B) Quantification of the peak delayed rectifier current density at $+40 \mathrm{mV}$. The current densities measured in the first week of terminal differentiation were significantly higher than all later measurements. (C) Representative traces of the transient outward $\mathrm{K}^{+}$current in hES cell-derived neurons. (D) Quantification of the peak transient outward current density at $+40 \mathrm{mV}$. Current densities significantly increased from week 1 to week 2 and then again at week $3 . n=7(1 \mathrm{w}), 9(2 \mathrm{w}), 11(3 \mathrm{w}), 12(4 \mathrm{w}) .{ }^{* *} P<0.01,{ }^{* * *} P<0.001,{ }^{* \#} P<0.01$ as

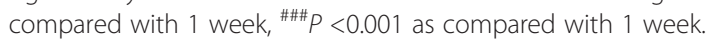

by using the Hoechst tag, and TUNEL staining was used to assess cell death. Although there was some TUNEL staining present in the graft area, co-localization with Hoechst-positive cells was negligible (Figure 5A). Cell survival was further indicated by the fact that the Hoechst tag was still visible in a large number of cells in the stroke core and penumbra of transplant animals after 28 days in vivo (Figure 5B-b). Hoechst 33342-positive cells in the grafted core/peri-infarct region were 5,541 \pm 180 (averaged total number from six sections per animals; $\mathrm{n}=3$ mice). Neuronal differentiation of transplanted cells was assessed by quantifying Hoechst 33342 co-localization with NeuN in the penumbra region (Figure $5 \mathrm{~B}-\mathrm{c}$ ). At day 28 , the percentage of Hoechst-positive cells that were also NeuNpositive was highly variable between animals, ranging from $13.5 \%$ to $40.8 \%$, and the mean value was $20.6 \% \pm 10.3 \%$. Hoechst 33342 co-localization with MAP2 was also observed (data not shown), further indicating neuronal differentiation. Some Hoechst-positive cells $(14.6 \% \pm 2.4 \%)$ did co-localize with vessels, but whether the cells were part of the vessels or migrating along them was not clear.

\section{Transplantation increases the proportion of} bromodeoxyuridine-positive neurons at 28 days

Animals received daily injections of BrdU beginning on the day of the transplant in order to track the fate of newborn cells. No difference in the total number of BrdUpositive cells in the penumbra was observed between animals receiving cell transplantation and medium controls. However, the percentage of BrdU-positive cells colocalized with NeuN was $9.6 \% \pm 0.5 \%$ in the transplant group $(n=8)$, which is significantly higher than the $5.2 \% \pm$ $0.7 \%$ observed in the control group $(n=6)$ (Figure 6). This indicates an increase in the number of newborn neurons in the transplant group, although BrdU may also be incorporated into cells undergoing DNA repair. The fact that the total density of BrdU-positive cells was not increased in the transplant group suggests that proliferation in the graft was low. This supports the hypothesis that BrdU incorporation represents endogenous regenerative activity but does not fully exclude the contribution of proliferation or repair in graft-derived cells.

The number of BrdU-positive cells co-localized with Col IV was examined as a marker of angiogenesis. In 

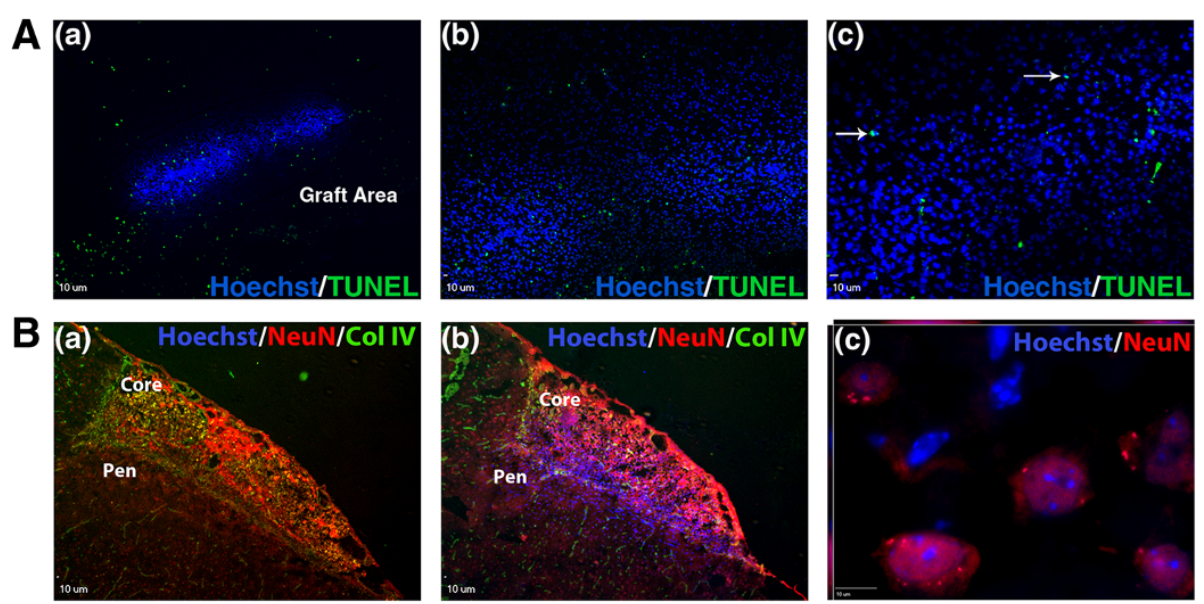

Figure 5 hES cell-derived neural precursors survive and differentiate into neurons in vivo. (A) Representative example of graft survival 2 days after transplantation. The circle in (a) marks the graft area as determined by the Hoechst-tagged precursor cells. Arrows in (C) demonstrate occasional TUNEL co-localization with Hoechst-positive cells. (B) Representative images stained for NeuN (red) and collagen IV (green) 28 days after transplantation. No Hoechst-positive cells (blue) are evident in the medium control animal (a), whereas many transplanted cells are still present in the transplant animal (b). The high-power image in (c) demonstrates co-localization of Hoechst 33342 and NeuN in the penumbra region, indicating neuronal differentiation of transplanted cells. All scale bars $=10 \mu \mathrm{m}$.

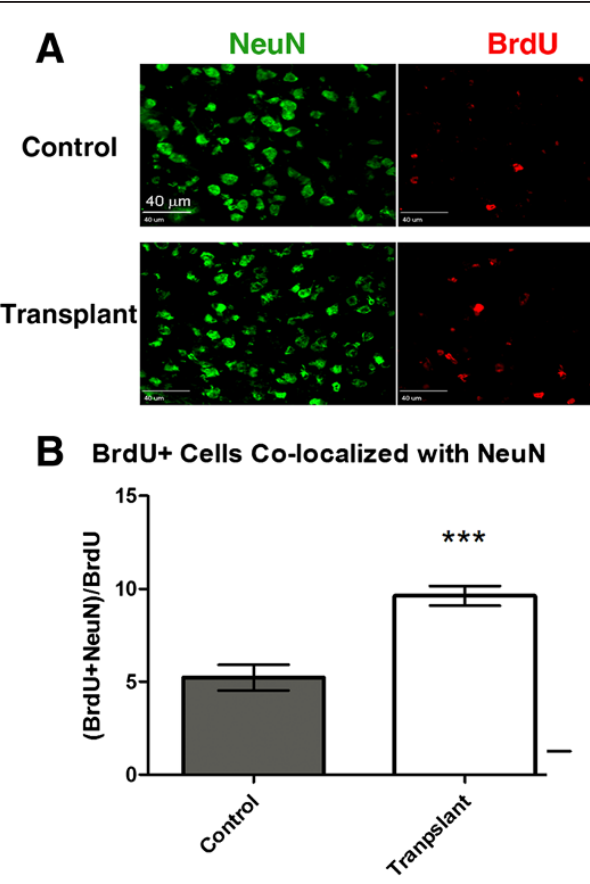

\section{BrdU+ Cells Co-localized with Col IV}

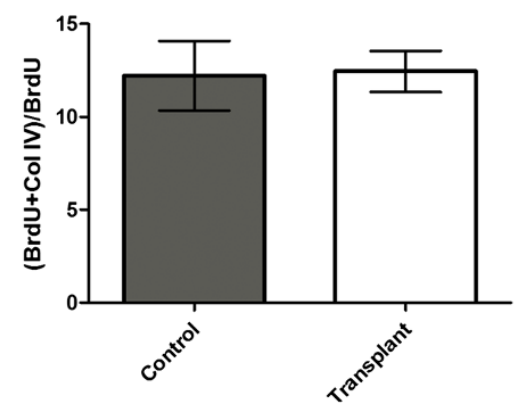

Figure 6 Transplantation of hES cell-derived neural precursors increases BrdU co-localization with NeuN. (A) Representative images of staining for NeuN (green), BrdU (red), and Col IV (blue) in the penumbra region of a medium control and a cell transplant animal. White arrows indicate co-localization of NeuN and BrdU. Scale bars $=40 \mu \mathrm{m}$. (B) A significantly higher percentage of BrdU-positive cells in the transplant animals co-localized with NeuN as compared with control animals, potentially indicating a higher degree of neurogenesis. ${ }^{* * *} P<0.001, n=6$ (control) and 8 (transplant). (C) No significant difference was observed in the percentage of BrdU-positive cells co-localized with Col IV, indicating no difference in angiogenesis. $\mathrm{n}=6$ (control) and 7 (transplant). 
this case, no significant increase was observed; $12.2 \% \pm$ $1.9 \%$ of BrdU-positive cells co-localized with Col IV in the control group $(\mathrm{n}=6)$ and $12.4 \% \pm 1.1 \%$ in the transplant group $(\mathrm{n}=7)(P>0.05$; Figure 6$)$.

Transplantation improves functional recovery after stroke Functional recovery was assessed by using the adhesive removal test. On the affected side, both the time to contact and the time to remove were significantly longer after stroke (Table 1). As expected, neither of these measures was significantly different in either group on the unaffected side. The post-stroke baseline measurements were not significantly different between the control and transplant groups (Table 2). The model-based estimate of the mean outcome measures at each time point was analyzed (Table 3). It is important to note that these are not absolute measurements but instead are estimates that incorporate the post-stroke impairment and the learning curve observed on the unaffected side. There was no significant difference between the outcome measures between the control and transplant groups at any of the four time points. However, the estimated slope over time in the mixed linear model of the longitudinal outcome measures reveals a significant decreasing trend in time to contact in the transplant group (estimated slope is $-0.15, P$ value $=0.012$ ). This trend is not observed in the control group (estimated slope is $0.06, P$ value $=0.314$ ) . The time to remove does not change significantly across time in either group. This suggests an improvement in the sensory function of the forepaw in transplant animals as compared with controls. Additionally, the variance of the control group was significantly higher than that of the transplant group in both measures, indicating a more consistent recovery in treated animals.

\section{Discussion}

This study details the use of a fully adherent and feederfree differentiation protocol employing small molecules to obtain neural precursors for transplantation after stroke. Although there is still some batch-to-batch variation and some animal products are still used, this protocol reduces the heterogeneity present in suspension culture and reduces possible contamination from animal products by removing the use of feeder cells in cell culture. Here, we

Table 1 Performance in the adhesive removal task is significantly altered by stroke

\begin{tabular}{llcc}
\hline \multicolumn{2}{c}{ Measurements } & $\begin{array}{c}\text { Control group } \\
(\mathbf{n}=\mathbf{1 7})\end{array}$ & $\begin{array}{c}\text { Transplant group } \\
(\mathbf{n}=\mathbf{1 8})\end{array}$ \\
\hline Affected side & Time to contact & $P=0.001$ & $P=0.001$ \\
& Time to remove & $P<0.0001$ & $P=0.0004$ \\
Unaffected side & Time to contact & $P=0.627$ & $P=0.255$ \\
& Time to remove & $P=0.220$ & $P=0.091$ \\
\hline
\end{tabular}

demonstrate that neural precursors derived by using this protocol can develop into electrophysiologically active neurons, suggesting that they have the potential to act as functional neurons in damaged tissue. We further demonstrate that neural precursors survive, differentiate into neurons, improve neural regeneration, and enhance sensory function after transplantation into the penumbra region of stroke.

As we demonstrated during terminal differentiation, it is possible for cells to express neuronal markers like NeuN and neurofilament without exhibiting mature electrophysiological function. It is important to ensure that cells intended to replace lost tissue in the brain can further differentiate into neurons and that those neurons can respond appropriately to electrical signals. However, many studies rely on protein expression, without testing for electrophysiological function. Johnson et al. [28] studied functional development in hES cell-derived (H9) neurons over the course of 7 weeks of terminal differentiation (10 weeks from the onset of differentiation in hES cells). $\mathrm{PAX6}^{+} / \mathrm{SOX}^{+}$progenitors were obtained within 2 weeks by using suspension culture and neural rosette isolation, similar to our time course. These were again cultured in suspension for 1 week before plating for terminal differentiation in a medium containing brain-derived neurotrophic factor and glial cell linederived neurotrophic factor, among other factors. Electrophysiological properties were examined at 1, 3, 4, and 7 weeks after plating for terminal differentiation. Highamplitude, single-spike action potentials were first reported at 4 weeks of terminal differentiation, and repetitive trains were observed in some cells at 7 weeks. In contrast, we obtained high-amplitude, single-spike action potentials at only 2 weeks after plating for terminal differentiation, and bFGF was the only growth factor added to our base medium. We began to obtain repetitive trains at 3 weeks of terminal differentiation, and the proportion of cells firing them increased with another week of culture. We have therefore greatly reduced the time and cost associated with obtaining electrophysiologically active neurons in vitro. After transplantation, cells differentiated into neuronal cells. Although the present study could not verify the electrophysiological properties of these cells, behavioral tests support the hypothesis that the transplanted cells participated in functional repair of damaged brain structures.

In this study, we examined neuronal differentiation in vitro to confirm the ability of our hES cell-derived neural precursors to further differentiate into neurons. While these neurons were expressing receptor subunits and electrical activity consistent with an excitatory phenotype, we did not determine the exact subtype of neurons we derived in vitro. This determination, along with how environments approximating the stroke and 
Table 2 No difference was found between groups in post-stroke performance

\begin{tabular}{llccc}
\hline & Measurements & Control group & Transplant group & \\
$(\mathbf{n}=\mathbf{1 7})$ & $\boldsymbol{P}$ value \\
& & $10.78 \pm 15.17$ & $9.26 \pm 10.33$ & 0.644 \\
\hline Affected side & Time to contact & $11.24 \pm 8.02$ & $20.25 \pm 32.48$ & 0.381 \\
& Time to remove & $3.16 \pm 3.90$ & $2.65 \pm 2.96$ & 0.842 \\
Unaffected side & Time to contact & $5.97 \pm 2.40$ & $7.33 \pm 4.13$ & 0.363 \\
& Time to remove & & \\
\hline
\end{tabular}

penumbra region affect the differentiation, will be important as therapies move toward the clinic. To this same end, it will be important to further identify the non-neuronal cells in culture with an emphasis on demonstrating that the cell types derived become postmitotic upon differentiation and do not form any inappropriate cell types. In this study, we used bFGF as our only recombinant growth factor, but it is possible that further patterning factors will increase the proportion of neurons in culture and permit the derivation of specific subtypes. Patterning factors are usually recombinant growth factors that can greatly increase the cost of culture, but small molecules may lead to decreased cost in this arena as well. For example, purmorphamine is a sonic hedgehog (shh) agonist that has been used in the derivation of dopaminergic neurons [53].

In vivo, we observed a very high degree of cell survival after transplantation. This may have been due, in part, to the presence of Matrigel throughout the differentiation process. It was recently reported that hES cellderived neural precursors cultured with Matrigel before transplantation or injected with a Matrigel scaffold reduced infarct size, improved behavioral outcomes, and differentiated primarily into neuronal cells [22]. However, cells that were not exposed to Matrigel exhibited high levels of cell death and lower proportions of neuronal markers and did not improve infarct size or behavioral outcomes. We have also reported positive effects of Matrigel on hES cell-derived neural precursors in vitro, where we found that cells terminally differentiated on poly-D-lysine/laminin-coated dishes never developed mature action potential responses but that those grown on Matrigel-coated dishes did [40]. Thus, the use of
Matrigel throughout our differentiation process may have contributed to the positive results we report here. However, Matrigel will need to be removed from the process if it is ever used in human trials, as the removal of xenogenic products is largely seen as necessary for widespread clinical use [54].

One major concern with the use of pluripotent stem cells in cell therapy is the fear of tumor formation. We did not observe any teratoma formation and this was likely due the lack of residual pluripotent cells in our cultures. However, pluripotent cells need not be present for tumor formation. For example, small rosette-like tumors can form if hES cell-derived neural precursors are transplanted at a stage of differentiation in which cells are highly proliferative but not yet similar to fetal brain in the expression of neural markers [24]. These cells expressed high levels of PAX6 but had only low-level expression of SOX1, whereas the neural precursor stage, which did not result in any tumor formation, expressed high levels of both markers. The cells we obtain with small-molecule SMAD inhibition also highly expressed both of these markers, and we observed no adverse effects from cell proliferation in the brain tissue. In fact, the total numbers of BrdU-positive cells found in the control and transplant groups were not significantly different, suggesting low levels of proliferation in the graft.

Another concern in our model may have been the use of the Hoechst tag for tracking, as it has the potential to cause problems in DNA replication or leak into neighboring cells. However, this tag has been successfully used in prior studies [17], and we did not observe any tumor formation in vivo. As argued earlier, it is likely that the transplanted cells were not proliferative, mitigating any problems with

Table 3 Time to contact improves over time in animals receiving transplant

\begin{tabular}{|c|c|c|c|c|c|c|c|}
\hline \multicolumn{2}{|c|}{ Measurements } & \multicolumn{4}{|c|}{ Estimated mean (SE) } & \multicolumn{2}{|c|}{ Slope across time } \\
\hline & & 7 days & 14 days & 21 days & 28 days & Estimated slope (SE) & $P$ value \\
\hline \multirow[t]{3}{*}{ Time to contact } & Transplant & $7.19(1.20)$ & $5.06(1.19)$ & $4.65(1.19)$ & $3.75(1.18)$ & $-0.15(0.06)$ & 0.012 \\
\hline & Control & $5.87(1.26)$ & $4.21(1.22)$ & $4.79(1.22)$ & $4.11(1.22)$ & $-0.06(0.06)$ & 0.314 \\
\hline & $P$ value & 0.442 & 0.617 & 0.936 & 0.833 & & \\
\hline \multirow[t]{3}{*}{ Time to remove } & Transplant & $10.74(0.95)$ & $9.30(0.95)$ & $9.55(0.95)$ & $10.10(0.95)$ & $-0.02(0.05)$ & 0.652 \\
\hline & Control & $9.95(0.97)$ & $7.99(0.96)$ & $9.55(0.97)$ & $10.21(0.99)$ & $0.04(0.05)$ & 0.497 \\
\hline & $P$ value & 0.567 & 0.351 & 0.998 & 0.936 & & \\
\hline
\end{tabular}

SE standard error. 
DNA replication. In future studies, a better tracking method may be something akin to that used by Daadi et al. [25]. Transfection of cells with an easily identifiable marker that does not leak and can be easily co-stained would be ideal. The additional inclusion of a bioluminescent marker or superparamagnetic iron oxide (SPIO) tag would also allow for in vivo monitoring in live animals.

A different tracking method would also help to better differentiate between endogenous and graft-derived neurogenesis. In previous studies with this stroke model, we have shown that newborn cells that express doublecortin (DCX) and incorporate BrdU migrate from the SVZ to the stroke region and form new neurons. Other interventions, such as whisker stimulation, can increase the number of neuroblasts migrating toward the stroke region at early time points and new neurons in the penumbra region 4 weeks after stroke [55]. This response could be enhanced by the transplantation of neural precursors, but this hypothesis remains to be verified by using more specific markers and technologies.

BrdU incorporation is the most commonly used and clearest measure for tracking the fate of newborn cells in the nervous system [56,57], as it remains in the cell even after it differentiates and leaves the cell cycle, but there are concerns with its use. Because BrdU incorporates during DNA replication, it is possible that labeled cells may have been undergoing cell repair (successfully or prior to apoptosis) rather than mitosis [58]. In unpublished studies, we have found little to no co-staining of TUNEL and BrdU in this model, and none of the counted cells showed morphological signs of apoptosis or necrosis, so it is unlikely that the BrdU-positive cells we observed were dying. It is also unlikely that our dose of $50 \mathrm{mg} / \mathrm{kg}$ would be sufficient to visualize cells undergoing repair [59], although an increase in successful cell repair would also be a desirable outcome of transplantation. Future studies will need to differentiate between cell repair and true neurogenesis by examining earlier time points and quantifying DCX-positive neuroblasts migrating to the stroke region after treatment.

Our previous unpublished studies have demonstrated no change in graft survival in this model when immune suppression is administered and we chose not to use it in this study. However, it is possible that we would have been able to achieve greater or more consistent levels of neuronal differentiation in vivo if immune suppression had been used. In a transplant model using mouse embryonic stem-cell derived neurospheres, graft survival was unchanged by the administration of cyclosporine A, but inflammatory factors biased cells toward glial differentiation rather than neuronal differentiation when it was not given [60]. This may have occurred in our model as well, although we likely mitigated this effect by transplanting 7 days after stroke, when inflammation in the stroke region has largely subsided. It is also important to note that immune suppression may be detrimental to healing after stroke. Inflammatory signals can attract stem cells to the site of injury [61], and the immune response may be neuroprotective and necessary for endogenous neurogenesis [62-65]. Additionally, the immune system is already naturally suppressed after stroke [66], and further suppression may increase the risks of infection and tumor formation $[67,68]$. It is thus clear that systemic immune suppression in patients with stroke should be avoided wherever possible.

\section{Conclusions}

We have demonstrated that neural precursors derived from hES cells by using small-molecule SMAD inhibition in a fully adherent protocol can differentiate into neurons both in vitro and in vivo after transplantation into the ischemic brain. This protocol reduces the heterogeneity, cost, and use of animal products in obtaining hES cell-derived neural precursors that can differentiate into electrophysiologically active neurons and allows for transplantation at a safe stage of differentiation. Transplantation of these cells improves regenerative activities and sensory function even without immune suppression. Further studies will be needed to fully characterize the integration of these cells into the damaged tissue and the paracrine effects on endogenous healing.

\section{Abbreviations}

AMPA: 2-amino-3-(3-hydroxy-5-methyl-isoxazol-4-yl)propanoic acid; AP: Alkaline phosphatase; bFGF: Basic fibroblast growth factor; BrdU: Bromodeoxyuridine; CCA: Common carotid arteries; Col IV: Collagen IV; DCX: Doublecortin; GFAP: Glial fibrillary acidic protein; hES: Human embryonic stem; HRP: Horseradish peroxidase; MAP2: Microtubule-associated protein 2; NeuN: Neuronal nuclei; NF: Neurofilament L; NMDA: N-methyl-Daspartic acid; PAX6: Paired box gene 6; SEM: Standard error of the mean; SOX1: Sex-determining region Y-box 1; SVZ: Subventricular zone; TUNEL: Terminal deoxynucleotidyl transferase dUTP nick end labeling.

\section{Competing interests}

The authors declare that they have no competing interests.

\section{Authors' contributions}

DD-S carried out the cell and tissue processing, staining, Western blots, and most statistical analyses; participated in the study design; and drafted the manuscript. MS carried out the electrophysiological measurements. OM aided in cell culture, study design, and manuscript revision. YG designed and carried out the statistical analysis of the adhesive removal tests and contributed to the drafting of the manuscript. XG carried out all animal surgeries. DC aided in immunohistochemistry and cell quantification. LW helped in initiation of the research idea, participated in the study design, and revised the manuscript. All authors read and approved the final manuscript.

\section{Acknowledgments}

This work was supported by National Institutes of Health $(\mathrm{NIH})$ grants NS0458710, NS 057255, NS075338, and NS062097. This work was also supported by the NIH grant C06 RR015455 from the Extramural Research Facilities Program of the National Center for Research Resources. Some of the data presented here were included in a dissertation by DD-S that will be published by Proquest/UMI Dissertation Publishing. The authors are grateful for helpful discussion with Shan Ping Yu and his support during this investigation. 


\section{Author details}

'Department of Anesthesiology, Emory University, 101 Woodruff Circle, Atlanta, GA 30322, USA. ²Department of Biomedical Engineering, Georgia Institute of Technology, 15 Ferst Drive, NW, Atlanta, GA 30332, USA. ${ }^{3}$ Department of Biostatistics and Bioinformatics, Emory University, 1518 Clifton Road, NE, Atlanta, GA 30322, USA.

Received: 11 January 2013 Revised: 25 January 2013

Accepted: 26 July 2013 Published: 8 August 2013

\section{References}

1. Roger VL, Go AS, Lloyd-Jones DM, Benjamin EJ, Berry JD, Borden WB, Bravata DM, Dai S, Ford ES, Fox CS, Fullerton HJ, Gillespie C, Hailpern SM, Heit JA, Howard VJ, Kissela BM, Kittner SJ, Lackland DT, Lichtman JH, Lisabeth LD, Makuc DM, Marcus GM, Marelli A, Matchar DB, Moy CS, Mozaffarian D, Mussolino ME, Nichol G, Paynter NP, Soliman EZ, Sorlie PD, Sotoodehnia N, Turan TN, Virani SS, Wong ND, Woo D, Turner MB, American Heart Association Statistics Committee and Stroke Statistics Subcommittee: Executive summary: heart disease and stroke statistics-2012 update: a report from the American Heart Association. Circulation 2012, 125:188-197.

2. Durukan A, Tatlisumak T: Acute ischemic stroke: overview of major experimental rodent models, pathophysiology, and therapy of focal cerebral ischemia. Pharmacol Biochem Behav 2007, 87:179-197.

3. Hrenreich H, Weissenborn K, Prange H, Schneider D, Weimar C, Wartenberg K, Schellinger PD, Bohn M, Becker $H$, Wegrzyn M, Jähnig P, Herrmann M, Knauth M, Bähr M, Heide W, Wagner A, Schwab S, Reichmann H, Schwendemann G, Dengler R, Kastrup A, Bartels C, EPO Stroke Trial Group: Recombinant human erythropoietin in the treatment of acute ischemic stroke. Stroke 2009, 40:e647-e656.

4. Wei L, Keogh CL, Whitaker VR, Theus MH, Yu SP: Angiogenesis and stem cell transplantation as potential treatments of cerebral ischemic stroke. Pathophysiology 2005, 12:47-62.

5. Yu D, Silva GA: Stem cell sources and therapeutic approaches for central nervous system and neural retinal disorders. Neurosurg Focus 2008, 24:E11.

6. Hess DC, Borlongan CV: Cell-based therapy in ischemic stroke. Expert Rev Neurother 2008, 8:1193-1201.

7. Pollock K, Stroemer P, Patel S, Stevanato L, Hope A, Miljan E, Dong Z, Hodges H, Price J, Sinden JD: A conditionally immortal clonal stem cell line from human cortical neuroepithelium for the treatment of ischemic stroke. Exp Neurol 2006, 199:143-155.

8. Stevanato L, Corteling RL, Stroemer P, Hope A, Heward J, Miljan EA, Sinden JD: c-MycERTAM transgene silencing in a genetically modified human neural stem cell line implanted into MCAo rodent brain. BMC Neurosci 2009, 10:86.

9. Mack GS: ReNeuron and StemCells get green light for neural stem cell trials. Nat Biotechnol 2011, 29:95-97.

10. Jin K, Xie L, Mao X, Greenberg MB, Moore A, Peng B, Greenberg RB, Greenberg DA: Effect of human neural precursor cell transplantation on endogenous neurogenesis after focal cerebral ischemia in the rat. Brain Res 2011, 1374:56-62.

11. Bliss TM, Kelly S, Shah AK, Foo WC, Kohli P, Stokes C, Sun GH, Ma M, Masel J, Kleppner SR, Schallert T, Palmer T, Steinberg GK: Transplantation of hNT neurons into the ischemic cortex: cell survival and effect on sensorimotor behavior. J Neurosci Res 2006, 83:1004-1014.

12. Hara K, Yasuhara T, Maki M, Matsukawa N, Masuda T, Yu SJ, Ali M, Yu G, Xu L, Kim SU, Hess DC, Borlongan CV: Neural progenitor NT2N cell lines from teratocarcinoma for transplantation therapy in stroke. Prog Neurobiol 2008, 85:318-334.

13. Zhang P, Li J, Liu Y, Chen X, Kang Q: Transplanted human embryonic neural stem cells survive, migrate, differentiate and increase endogenous nestin expression in adult rat cortical peri-infarction zone. Neuropathology 2009, 29:410-421.

14. Andres RH, Horie N, Slikker W, Keren-Gill H, Zhan K, Sun G, Manley NC, Pereira MP, Sheikh LA, McMillan EL, Schaar BT, Svendsen CN, Bliss TM, Steinberg GK: Human neural stem cells enhance structural plasticity and axonal transport in the ischaemic brain. Brain 2011, 134:1777-1789.

15. Nakagomi N, Nakagomi T, Kubo S, Nakano-Doi A, Saino O, Takata M, Yoshikawa H, Stern DM, Matsuyama T, Taguchi A: Endothelial cells support survival, proliferation, and neuronal differentiation of transplanted adult ischemia-induced neural stem/progenitor cells after cerebral infarction. Stem Cells 2009, 27:2185-2195.

16. Prajerova I, Honsa P, Chvatal A, Anderova M: Neural stem/progenitor cells derived from the embryonic dorsal telencephalon of D6/GFP mice differentiate primarily into neurons after transplantation into a cortical lesion. Cell Mol Neurobiol 2010, 30:199-218.

17. Wei L, Cui L, Snider BJ, Rivkin M, Yu SS, Lee CS, Adams LD, Gottlieb DI, Johnson EM Jr, Yu SP, Choi DW: Transplantation of embryonic stem cells overexpressing $\mathrm{BCl}-2$ promotes functional recovery after transient cerebral ischemia. Neurobiol Dis 2005, 19:183-193.

18. Yanagisawa D, Qi M, Kim DH, Kitamura Y, Inden M, Tsuchiya D, Takata K, Taniguchi T, Yoshimoto K, Shimohama S, Akaike A, Sumi S, Inoue K: Improvement of focal ischemia-induced rat dopaminergic dysfunction by striatal transplantation of mouse embryonic stem cells. Neurosci Lett 2006, 407:74-79.

19. Theus MH, Wei L, Cui L, Francis K, Hu X, Keogh C, Yu SP: In vitro hypoxic preconditioning of embryonic stem cells as a strategy of promoting cell survival and functional benefits after transplantation into the ischemic rat brain. Exp Neurol 2008, 210:656-670.

20. Daadi MM, Maag AL, Steinberg GK: Adherent self-renewable human embryonic stem cell-derived neural stem cell line: functional engraftment in experimental stroke model. PLOS One 2008, 3:e1644.

21. Kim DY, Park SH, Lee SU, Choi DH, Park HW, Paek SH, Shin HY, Kim EY, Park $\mathrm{SP}, \mathrm{Lim} \mathrm{JH}$ : Effect of human embryonic stem cell-derived neuronal precursor cell transplantation into the cerebral infarct model of rat with exercise. Neurosci Res 2007, 58:164-175.

22. Jin K, Mao X, Xie L, Galvan V, Lai B, Wang Y, Gorostiza O, Wang X, Greenberg DA: Transplantation of human neural precursor cells in Matrigel scaffolding improves outcome from focal cerebral ischemia after delayed postischemic treatment in rats. J Cereb Blood Flow Metab 2010, 30:534-544.

23. Jin K, Mao X, Xie L, Greenberg RB, Peng B, Moore A, Greenberg MB, Greenberg DA: Delayed transplantation of human neural precursor cells improves outcome from focal cerebral ischemia in aged rats. Aging Cell 2010, 9:1076-1083.

24. Seminatore $C$, Polentes J, Ellman D, Kozubenko N, Itier V, Tine S, Tritschler L, Brenot M, Guidou E, Blondeau J, Lhuillier M, Bugi A, Aubry L, Jendelova P, Sykova E, Perrier AL, Finsen B, Onteniente B: The postischemic environment differentially impacts teratoma or tumor formation after transplantation of human embryonic stem cell-derived neural progenitors. Stroke 2010, 41:153-159.

25. Daadi MM, Li Z, Arac A, Grueter BA, Sofilos M, Malenka RC, Wu JC, Steinberg GK: Molecular and magnetic resonance imaging of human embryonic stem cell-derived neural stem cell grafts in ischemic rat brain. Mol Ther 2009, 17:1282-1291.

26. Darsalia V, Allison SJ, Cusulin C, Monni E, Kuzdas D, Kallur T, Lindvall O, Kokaia Z: Cell number and timing of transplantation determine survival of human neural stem cell grafts in stroke-damaged rat brain. J Cereb Blood Flow Metab 2011, 31:235-242.

27. Smukler SR, Runciman SB, Xu S, van der Kooy D: Embryonic stem cells assume a primitive neural stem cell fate in the absence of extrinsic influences. J Cell Biol 2006, 172:79-90.

28. Johnson MA, Weick JP, Pearce RA, Zhang SC: Functional neural development from human embryonic stem cells: accelerated synaptic activity via astrocyte coculture. J Neuroimmune Pharmacol 2007, 27:3069-3077

29. Cohen MA, Itsykson P, Reubinoff BE: Neural differentiation of human ES cells. Curr Protoc Cell Biol 2007, Chapter 23:Unit 23.7.

30. Kim DS, Lee JS, Leem JW, Huh YJ, Kim JY, Kim HS, Park IH, Daley GQ, Hwang DY, Kim DW: Robust enhancement of neural differentiation from human ES and iPS cells regardless of their innate difference in differentiation propensity. Stem Cell Rev 2010, 6:270-281.

31. Morizane A, Doi D, Kikuchi T, Nishimura K, Takahashi J: Small-molecule inhibitors of bone morphogenic protein and activin/nodal signals promote highly efficient neural induction from human pluripotent stem cells. J Neurosci Res 2011, 89:117-126.

32. Tavakoli T, Xu X, Derby E, Serebryakova Y, Reid Y, Rao MS, Mattson MP, Ma W Self-renewal and differentiation capabilities are variable between human embryonic stem cell lines 13, 16 and BG01V. BMC Cell Biol 2009, 10:44.

33. Swistowski A, Peng J, Liu Q, Mali P, Rao MS, Cheng L, Zeng X: Efficient generation of functional dopaminergic neurons from human induced 
pluripotent stem cells under defined conditions. Stem Cells 2010, 28:1893-1904

34. Vazin T, Chen J, Lee CT, Amable R, Freed WJ: Assessment of stromalderived inducing activity in the generation of dopaminergic neurons from human embryonic stem cells. Stem Cells 2008, 26:1517-1525.

35. Lee H, Shamy GA, Elkabetz Y, Schofield CM, Harrsion NL, Panagiotakos G, Socci ND, Tabar V, Studer L: Directed differentiation and transplantation of human embryonic stem cell-derived motoneurons. Stem Cells 2007, 25:1931-1939.

36. Itsykson P, llouz N, Turetsky T, Goldstein RS, Pera MF, Fishbein I, Segal M, Reubinoff BE: Derivation of neural precursors from human embryonic stem cells in the presence of noggin. Mol Cell Neurosci 2005, 30:24-36.

37. Chambers SM, Fasano CA, Papapetrou EP, Tomishima M, Sadelain M, Studer L: Highly efficient neural conversion of human ES and iPS cells by dual inhibition of SMAD signaling. Nat Biotechnol 2009, 27:275-280.

38. Gerrard L, Rodgers L, Cui W: Differentiation of human embryonic stem cells to neural lineages in adherent culture by blocking bone morphogenetic protein signaling. Stem Cells 2005, 23:1234-1241.

39. Zhou J, Su P, Li D, Tsang S, Duan E, Wang F: High-efficiency induction of neural conversion in human ESCS and human induced pluripotent stem cells with a single chemical inhibitor of transforming growth factor beta superfamily receptors. Stem Cells 2010, 28:1741-1750.

40. Drury-Stewart DSM, Mohamad O, Yu SP, Wei L: Small molecule promoted adherent and feeder free differentiation of functional neurons from human embryonic and induced pluripotent stem cells. J Stem Cells 2012, $6: 1-8$

41. Whitaker VR, Cui L, Miller S, Yu SP, Wei L: Whisker stimulation enhances angiogenesis in the barrel cortex following focal ischemia in mice. J Cereb Blood Flow Metab 2007, 27:57-68.

42. Francis KR, Wei L: Human embryonic stem cell neural differentiation and enhanced cell survival promoted by hypoxic preconditioning. Cell Death Disease 2010, 1:e22.

43. Wei $L$, Rovainen CM, Woolsey TA: Ministrokes in rat barrel cortex. Stroke 1995, 26:1459-1462.

44. Wei L, Craven K, Erinjeri J, Liang GE, Bereczki D, Rovainen CM, Woolsey TA, Fenstermacher JD: Local cerebral blood flow during the first hour following acute ligation of multiple arterioles in rat whisker barrel cortex. Neurobiol Dis 1998, 5:142-150.

45. Wei L, Erinjeri JP, Rovainen CM, Woolsey TA: Collateral growth and angiogenesis around cortical stroke. Stroke 2001, 32:2179-2184.

46. Bouet V, Boulouard M, Toutain J, Divoux D, Bernaudin M, Schumann-Bard P, Freret $\mathrm{T}$ : The adhesive removal test: a sensitive method to assess sensorimotor deficits in mice. Nat Protoc 2009, 4:1560-1564.

47. Michalczyk K, Ziman M: Nestin structure and predicted function in cellular cytoskeletal organisation. Histol Histopathol 2005, 20:665-671.

48. Walker AS, Goings GE, Kim Y, Miller RJ, Chenn A, Szele FG: Nestin reporter transgene labels multiple central nervous system precursor cells. Neural Plast 2010, 2010:894374.

49. Georgala PA, Carr CB, Price DJ: The role of Pax6 in forebrain development. Dev Neurobiol 2011, 71:690-709.

50. Georgala PA, Manuel M, Price DJ: The generation of superficial cortical layers is regulated by levels of the transcription factor Pax6. Cereb Cortex 2011, 21:81-94.

51. Simpson TI, Pratt T, Mason JO, Price DJ: Normal ventral telencephalic expression of Pax6 is required for normal development of thalamocortical axons in embryonic mice. Neural Dev 2009, 4:19.

52. Pevny LH, Sockanathan S, Placzek M, Lovell-Badge R: A role for SOX1 in neural determination. Development 1998, 125:1967-1978.

53. Stacpoole SR, Bilican B, Webber DJ, Luzhynskaya A, He XL, Compston A, Karadottir R, Franklin RJ, Chandran S: Efficient derivation of NPCs, spinal motor neurons and midbrain dopaminergic neurons from hESCs at $3 \%$ oxygen. Nat Protoc 2011, 6:1229-1240.

54. Lin G, Xu RH: Progresses and challenges in optimization of human pluripotent stem cell culture. Curr Stem Cell Res Ther 2010, 5:207-214.

55. Li WL, Yu SP, Ogle ME, Ding XS, Wei L: Enhanced neurogenesis and cell migration following focal ischemia and peripheral stimulation in mice. Dev Neurobiol 2008, 68:1474-1486.

56. Kee N, Sivalingam S, Boonstra R, Wojtowicz JM: The utility of Ki-67 and BrdU as proliferative markers of adult neurogenesis. J Neurosci Methods 2002, 115:97-105.
57. Landgren $H$, Curtis MA: Locating and labeling neural stem cells in the brain. J Cell Physiol 2011, 226:1-7.

58. Rakic P: Adult neurogenesis in mammals: an identity crisis. J Neurosci 2002, 22:614-618.

59. Cooper-Kuhn CM, Kuhn HG: Is it all DNA repair? Methodological considerations for detecting neurogenesis in the adult brain. Brain Res Dev Brain Res 2002, 134:13-21.

60. Ideguchi M, Shinoyama M, Gomi M, Hayashi H, Hashimoto N, Takahashi J: Immune or inflammatory response by the host brain suppresses neuronal differentiation of transplanted ES cell-derived neural precursor cells. J Neurosci Res 2008, 86:1936-1943.

61. Ben-Hur T, Ben-Menachem O, Furer V, Einstein O, Mizrachi-Kol R, Grigoriadis $\mathrm{N}$ : Effects of proinflammatory cytokines on the growth, fate, and motility of multipotential neural precursor cells. Mol Cell Neurosci 2003, 24:623-631.

62. Ziv Y, Avidan H, Pluchino S, Martino G, Schwartz M: Synergy between immune cells and adult neural stem/progenitor cells promotes functional recovery from spinal cord injury. Proc Natl Acad Sci USA 2006, 103:13174-13179.

63. Ziv Y, Ron N, Butovsky O, Landa G, Sudai E, Greenberg N, Cohen H, Kipnis J, Schwartz M: Immune cells contribute to the maintenance of neurogenesis and spatial learning abilities in adulthood. Nat Neurosci 2006, 9:268-275.

64. Beers DR, Henkel JS, Zhao W, Wang J, Appel SH: CD4+ T cells support glial neuroprotection, slow disease progression, and modify glial morphology in an animal model of inherited ALS. Proc Natl Acad Sci USA 2008, 105:15558-15563.

65. Chiu IM, Chen A, Zheng Y, Kosaras B, Tsiftsoglou SA, Vartanian TK, Brown RH Jr, Carroll MC: T lymphocytes potentiate endogenous neuroprotective inflammation in a mouse model of ALS. Proc Natl Acad Sci USA 2008 105:17913-17918.

66. Vogelgesang A, Dressel A: Immunological consequences of ischemic stroke: immunosuppression and autoimmunity. J Neuroimmunol 2011 231:105-110.

67. Dunn GP, Old LJ, Schreiber RD: The immunobiology of cancer immunosurveillance and immunoediting. Immunity 2004, 21:137-148.

68. Dunn GP, Bruce AT, Ikeda H, Old LJ, Schreiber RD: Cancer immunoediting: from immunosurveillance to tumor escape. Nat Immunol 2002, 3:991-998.

\section{doi: $10.1186 /$ scrt292}

Cite this article as: Drury-Stewart et al:: Highly efficient differentiation of neural precursors from human embryonic stem cells and benefits of transplantation after ischemic stroke in mice. Stem Cell Research \& Therapy 2013 4:93.

\section{Submit your next manuscript to BioMed Central and take full advantage of:}

- Convenient online submission

- Thorough peer review

- No space constraints or color figure charges

- Immediate publication on acceptance

- Inclusion in PubMed, CAS, Scopus and Google Scholar

- Research which is freely available for redistribution 